\title{
Gain Enhancement of Rectangular Microstrip Patch Antenna Designed for Exposure System Using Microstrip Array
}

\author{
Rahul Dev Mishra ${ }^{1}$ and Pramod Kumar Singhal ${ }^{2}$ \\ ${ }^{1}$ Department of Electronics Engineering, Madhav Institute of Technology and \\ Science, Gwalior \\ ${ }^{2}$ Department of Electronics Engineering, Madhav Institute of Technology and \\ Science, Gwalior \\ ${ }^{1}$ rahuldevmishra08@yahoo.co.in, ${ }^{2}$ pks_65@yahoo.com
}

\begin{abstract}
Microstrip patch antenna is a low profile antenna which has low gain and narrow bandwidth. In this paper a RMPA at $2.4835 \mathrm{GHz}$ is designed for mounting antenna in exposure system. Exposure system is a chamber made up of wood in which two antennas of same frequency mounted. One antenna is used for radiation while other one for reception. The RMPA designed using CST software with gain of $2.8647 \mathrm{~dB}$. In exposure system animals like rats can be placed for observing effects from Wi-Fi systems. These effects are applicable to humans also. For observing effects gain is not sufficient so there is need of gain enhancement. There are numerous techniques of gain enhancement but I proposed antenna array technique. Antenna array which is a collection of radiating elements are very versatile and synthesize a required pattern that can not be achieved using single element. So here two rectangular patches of same size and frequency connected as an array. The gain of array system is 5.6692 dB. Hence there is $97.89 \%$ increase in the gain of RMPA.
\end{abstract}

Keywords: Computer simulation technology (CST), Gain (IEEE), Rectangular Microstrip Patch antenna (RMPA), Microstrip array, Perfect electric conductor (PEC)

\section{Introduction}

As we know that we are surrounded with the electromagnetic waves and these waves are useful for humans for transmitting data from one place to another and play a very important role in our daily life but on the dark side these waves causing danger effects to the life of the humans and animals [1]. For example some birds are being extinct and humans are also having adverse health effects. The device that produces radiation is antenna here our concern is only to the microstrip antenna [2-3]. Due to thin profile configurations, conformity, low cost and small size a microstrip antenna [4-5] is widely used in compact and portable communication devices. Besides these remarkable advantages a patch has some serious drawbacks like low bandwidth (due to small size). The bandwidth can be increased but at the compromise of the size of the patch, making it large and bulky. Due to excitation of surface waves, patch antenna also suffers from reduced gain and efficiency. In this research work a rectangular microstrip [6] patch antenna is designed at $2.4835 \mathrm{GHz}$ with gain of $2.8647 \mathrm{~dB}$. The microstrip antenna is designed using CST software. This antenna will radiate signal and its effects are observed. In this proposed work the main aim is to increase the gain of the microstrip patch antenna. Many methods are there for increasing gain of the antenna for example using cylindrical electromagnetic crystal substrate [7]. By this crystal substrate the gain of the antenna is increased.

For example gain enhancement using PBG patch, reference patch gain is $3.41 \mathrm{~dB}$ while the gain with PBG patch [10] becomes $5.02 \mathrm{~dB}$. So increase is $47.21 \%$. 
In second paper in which gain enhancement using EBG structures [11] is discussed. Simulated gain for RMPA without EBG is $5.6 \mathrm{~dB}$ and with cylindrical EBG is $6 \mathrm{~dB}$. So increase is $7.14 \%$. But in my paper proposed method being used is antenna array because of $97.89 \%$ increase in gain and also this technique is very basic in which by combining two microstrip patch antenna of same size the gain of the antenna is increased.

\subsection{Antenna Array}

Usually the radiation pattern [14] of a single element is relatively wide, and each element provides low values of directivity (gain). In many applications it is necessary to design antennas with very directive characteristics (very high gains) to meet the demands of long distance communication. This can only be accomplished by increasing the electrical size of the antenna. Enlarging the dimensions of single elements often leads to more directive characteristics. Another way to enlarge the dimensions of the antenna, without necessarily increasing the size of the individual elements, is to form an assembly of radiating elements in an electrical and geometrical configuration. This new antenna, formed by multi-elements, is referred to as an array. In most cases, the elements of an array [8] are identical. This is not necessary, but it is often convenient, simpler, and more practical. The individual elements of an array may be of any form (wires, apertures, etc.). The total field of the array is determined by the vector addition of the fields radiated by the individual elements. This assumes that the current in each element is the same as that of the isolated element (neglecting coupling). This is usually not the case and depends on the separation between the elements. To provide very directive patterns, it is necessary that the fields from the elements of the array interfere constructively (add) in the desired directions and interfere destructively (cancel each other) in the remaining space. Ideally this can be accomplished, but practically it is only approached. In an array of identical elements, there are at least five controls that can be used to shape the overall pattern of the antenna. These are-

1. The geometrical configuration of the overall array (linear, circular, rectangular, spherical, etc.)

2. The relative displacement between the elements

3. The excitation amplitude of the individual elements.

4. The excitation phase of the individual elements

5. The relative pattern of the individual elements

The example of 4 element microstrip array is shown in figure 1 .

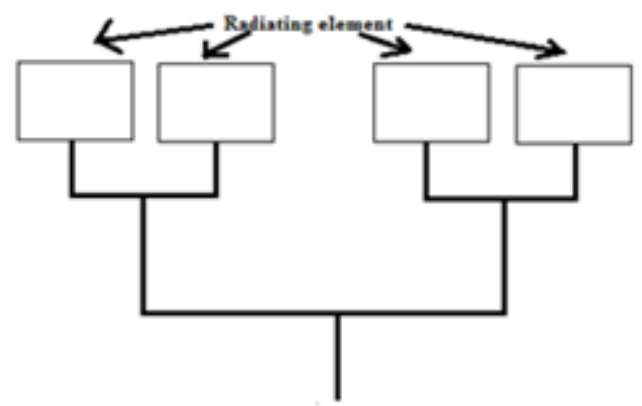

Figure 1. Four Element Patch Array 


\section{Antenna Design}

Before designing antenna [13], the first step is to consider the specification of the antenna based on its application. Based on research work, the various parameters are following in Table 1.

Table 1. Single Patch Antenna Design Specifications

\begin{tabular}{|c|c|c|}
\hline S.N. & PARAMETERS & VALUE \\
\hline 1. & Frequency & $2.4835 \mathrm{GHz}$ \\
\hline 2. & Substrate & FR4 \\
\hline 3. & Dielectric Constant & 4.3 \\
\hline 4. & Loss Tangent & 0.025 \\
\hline 5. & Substrate Height & $1.6 \mathrm{~mm}$ \\
\hline 6. & Conductor Thickness & $0.038 \mathrm{~mm}$ \\
\hline
\end{tabular}

The frequency $2.4835 \mathrm{GHz}$ is chosen because of widely used in WI-FI applications so here designed RMPA working as WI-FI antenna [9].

As for the substrate concern the major consideration will be dielectric constant and loss tangent. A high dielectric constant will result in a smaller patch size but this will generally reduce bandwidth efficiency and might have difficulty in fabricating a very small patch antenna size. A high loss tangent will reduce the antenna efficiency [12].

Comparison between FR4 and RT duroid substrate material is described in table 2.

Table 2. Comparison Between FR4 \& RT Duroid

\begin{tabular}{|c|c|c|c|}
\hline S.No. & PARAMETERS & FR4 & RT DUROID \\
\hline 1. & Dielectric constant & High & Low \\
\hline 2. & Patch size & Smaller & Large \\
\hline 3. & Loss tangent & High & Low \\
\hline 4. & Gain & Low & High \\
\hline 5. & Cost & Less & More \\
\hline
\end{tabular}

Due to small patch size, less cost and easily availability FR4 is preferred here.

The procedure for rectangular patch dimensions calculation is given below.

1. Specify $\boldsymbol{\epsilon}_{\mathrm{r}}, \mathrm{f}_{\mathrm{r}}$ in $\mathrm{Hz}$ and $\mathrm{h}$ (height of the substrate ) in $\mathrm{mm}$.

2. For an efficient radiator, a practical width that leads to good radiation efficiencies is $\mathrm{W}=\frac{1}{2 f_{r} \sqrt{\mu_{0} \epsilon_{0}}} \sqrt{\frac{2}{\epsilon_{r}+1}}=\frac{v_{0}}{2 f_{r}} \sqrt{\frac{2}{\epsilon_{r}+1}}$

3. Determine the effective dielectric constant of the microstrip antenna using equation given below $\boldsymbol{\epsilon}_{\text {reff }}=\frac{\epsilon_{r}+1}{2}+\frac{\epsilon_{r}-1}{2}\left[1+12 \frac{h}{W}\right]^{-0.5}$

4. Determine the extension of the length $\Delta \mathrm{L}$ using equation 3 .

5. The actual length of the patch can now be determined by using

$\mathrm{L}=\frac{1}{2 f_{r} \sqrt{\epsilon_{\text {reff }}} \sqrt{\mu_{0} \epsilon_{0}}}-2 \Delta L$ 


\subsection{Calculation}

From equation $1,2 \& 3$ we calculate

$\mathrm{W}=37.1025 \mathrm{~mm}$

$\mathrm{L}=28.7578 \mathrm{~mm}$

After calculation the designing of RMPA rectangular patch take place in CST software. CST MICROWAVE STUDIO® (CST MWS) is a specialist tool for the 3D EM simulation of high frequency components. CST MWS unparalleled performance making it first choice in technology leading R\&D departments.

CST MWS enables the fast and accurate analysis of high frequency (HF) devices such as antennas, filters, couplers, planar and multi-layer structures and SI and EMC effects. Exceptionally user friendly, CST MWS quickly gives you an insight into the EM behaviour of your high frequency designs.

CST promotes Complete Technology for 3D EM. Users of our software are given great flexibility in tackling a wide application range through the variety of available solver technologies. Beside the flagship module, the broadly applicable Time Domain solver and the Frequency Domain solver, CST MWS offers further solver modules for specific applications. Filters for the import of specific CAD files and the extraction of SPICE parameters enhance design possibilities and save time. In addition, CST MWS can be embedded in various industry standard workflows through the CST user interface.

\subsection{Design Procedure of RMPA-}

1. In the CST ground plane of length $55 \mathrm{~mm}$ and width of $50 \mathrm{~mm}$ with PEC material designed.

2. The height of ground plane is $0.038 \mathrm{~mm}$.

3. Above ground plane Substrate designed of same dimension as ground plane with height $1.6 \mathrm{~mm}$.

4. Above substrate rectangular patch of calculated length and width designed with height $0.038 \mathrm{~mm}$ and PEC material.

5. Feed of length $15 \mathrm{~mm} \&$ width $1 \mathrm{~mm}$ with height of $0.038 \mathrm{~mm}$.

This length and width of feed provides the best reflection coefficient of the rectangular patch antenna. The designed antenna in CST is given in figure 2.

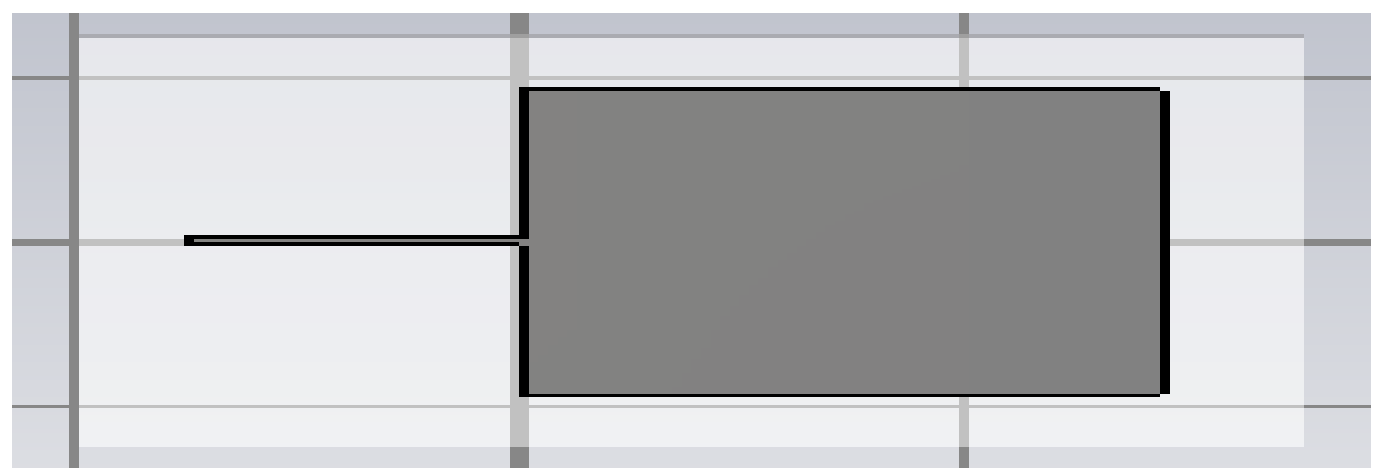

Figure 2. Rectangular Patch Antenna Designed at $2.4835 \mathrm{GHz}$ in CST

After designing rectangular patch antenna a discrete port is connected at the left most 
end of the feed line as shown in figure 3.

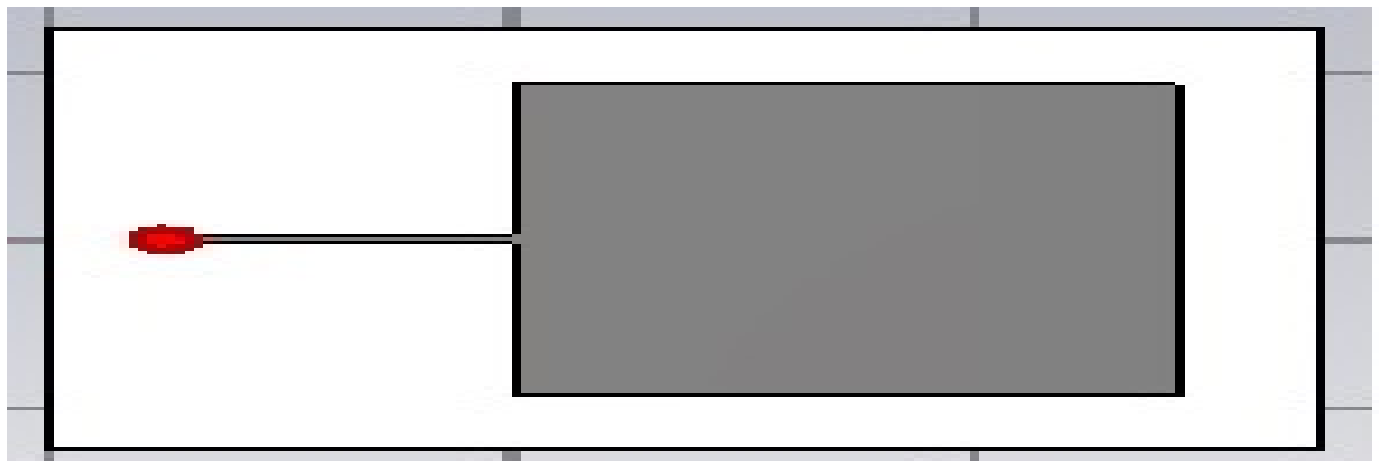

Figure 3. Rectangular Patch Antenna Designed at $2.4835 \mathrm{GHz}$ in CST with Discrete Port

After applying discrete port simulation is carried out using transient solver with accuracy of $-30 \mathrm{~dB}$. Simulator runs and provides the results. The graph for reflection coefficient is shown in figure 4.

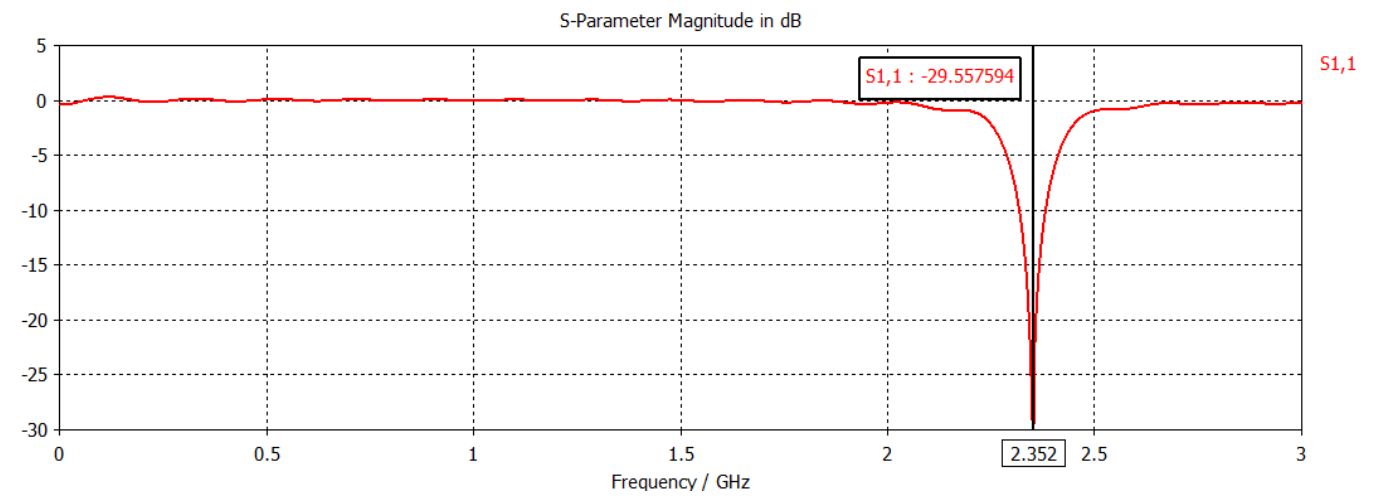

Figure 4. Reflection Coefficient of the Antenna

It can be seen from graph reflection coefficient of $-29.557594 \mathrm{~dB}$ or return loss of $29.557594 \mathrm{~dB}$ at a frequency of $2.352 \mathrm{GHz}$ is obtained. If the dip in the reflection loss is below the $-10 \mathrm{~dB}$ that means the antenna is radiating.

The VSWR shows the proper matching of patch with the feed and the value of VSWR should be nearest to 1 . Here the VSWR is calculated and shown in the figure 5 . The value for VSWR is 1.0688 at a frequency of $2.352 \mathrm{GHz}$. VSWR is dimension less quantity.

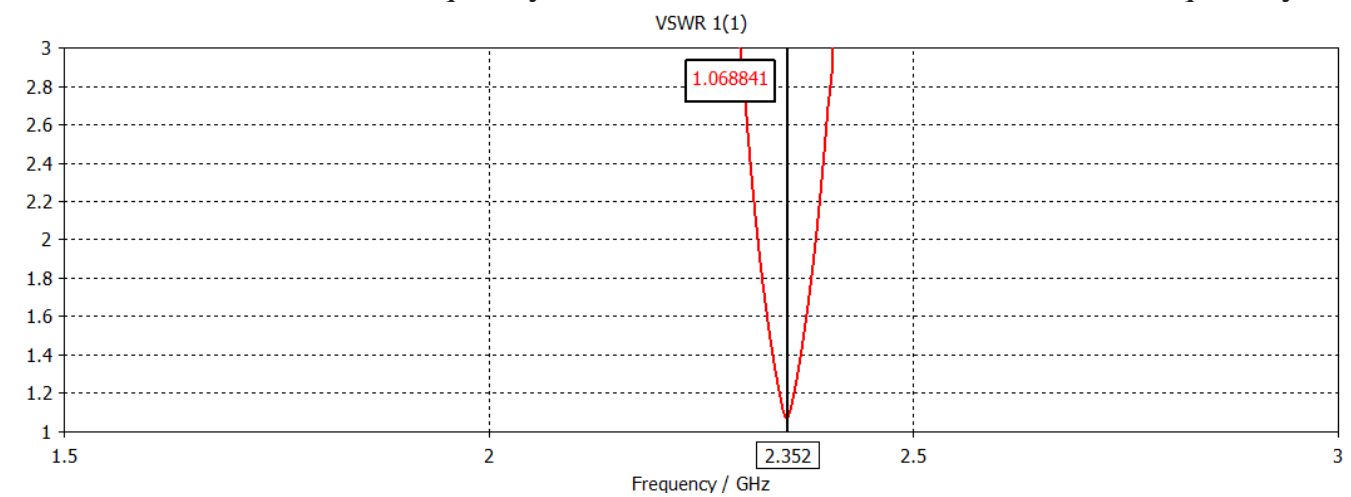

Figure 5. VSWR of the Antenna

The polar plot for this antenna at $2.4835 \mathrm{GHz}$ is plotted and shown in figure 6 . 
Gain Abs (Phi=0)

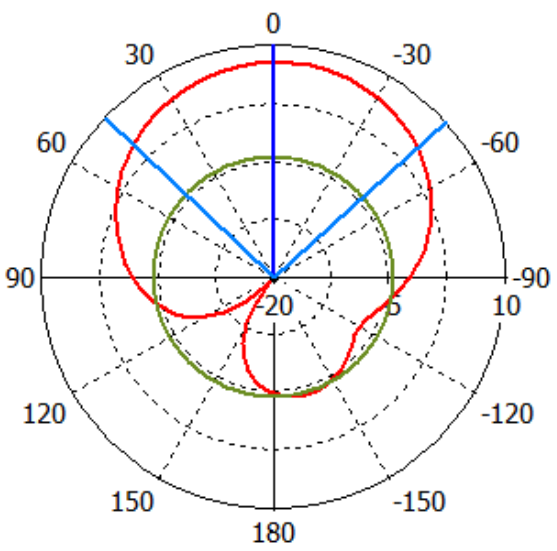

Theta / Degree vs. dB farfield (broadband) [1]

Figure 6. Polar Plot of the Antenna

The third dimensional view of the polar plot is shown in figure 7.

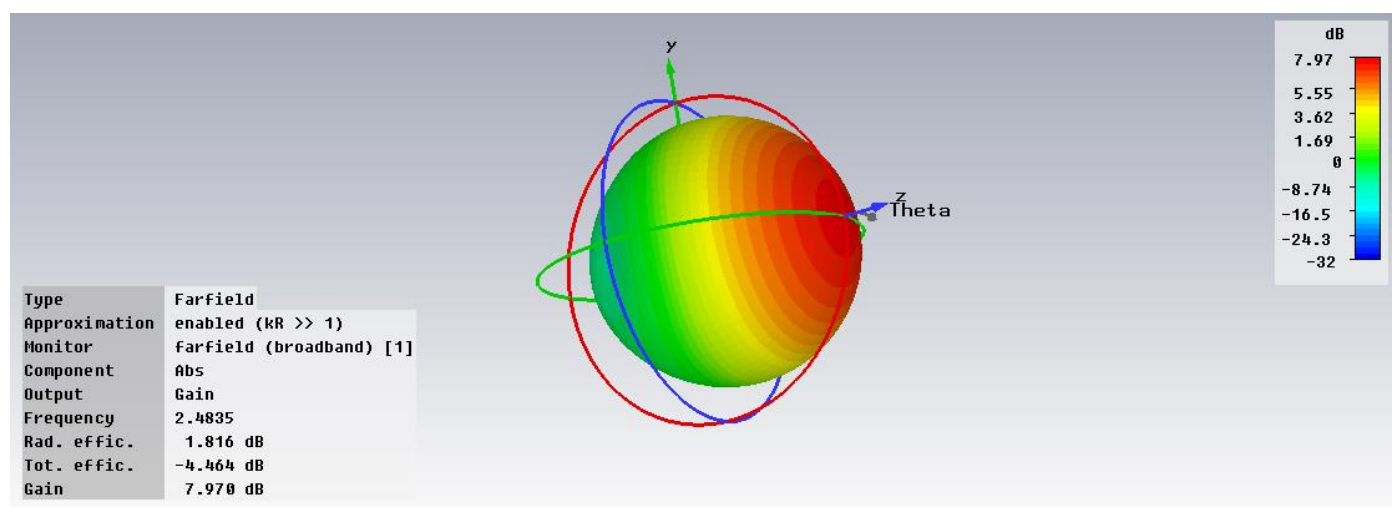

Figure 7. 3D View of Polar Plot of Antenna

And finally the important parameter gain (IEEE) is calculated which is our main concern of research. The gain (IEEE) at a frequency of $2.4828 \mathrm{GHz}$ is $2.8647 \mathrm{~dB}$ as shown in figure 8.

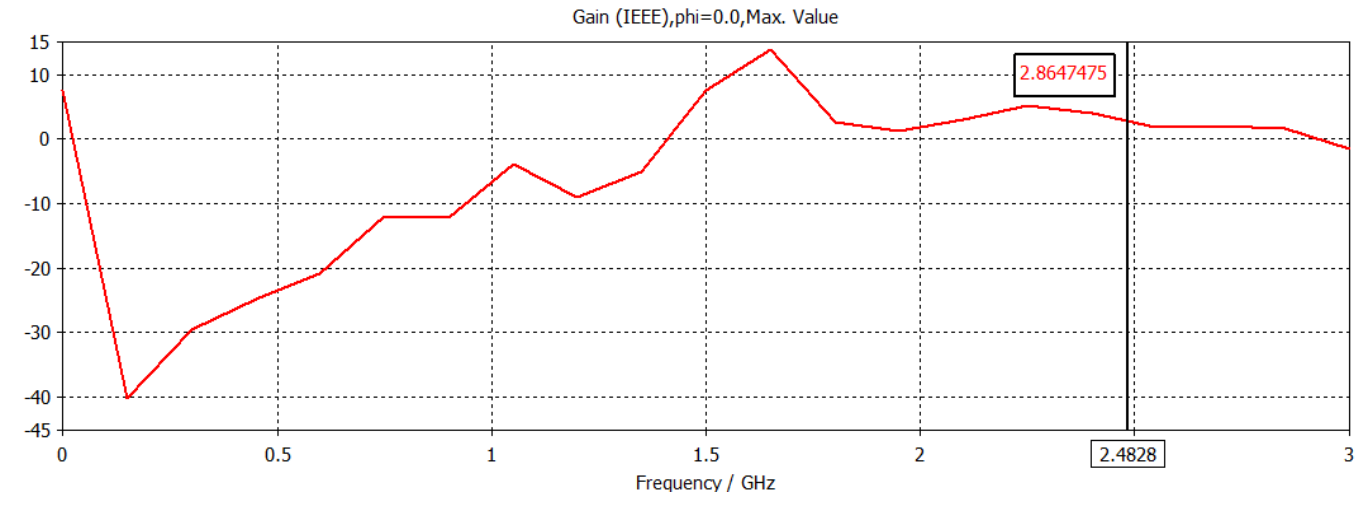

Figure 8. Gain (IEEE) of the Antenna 
So the gain has to be enhanced using combination of patches which is known as array. In the next section the array is designed.

\section{ARRAY DESIGNING IN CST}

Array is a collection of same radiating element. Here the two single rectangular patches are combined to achieve better results as shown in figure 9 .

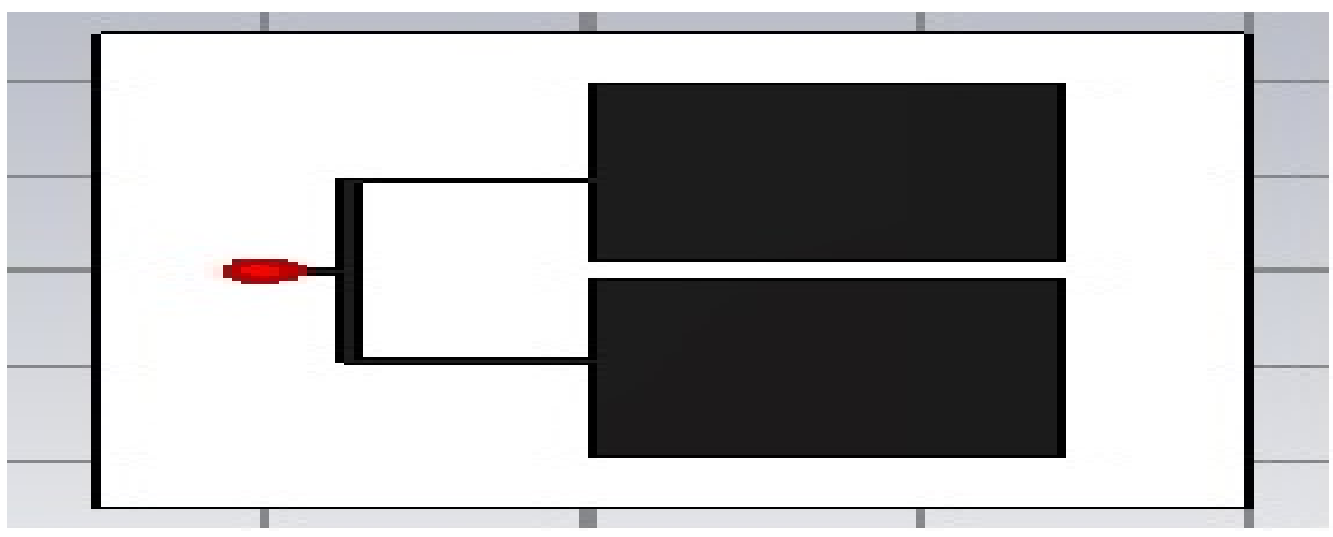

Figure 9. Two Element Array

In CST two rectangular patches of same width and length separated by $4 \mathrm{~mm}$ distance in y direction are designed. Patches are connected with feed lines and Dimensions of the feed lines are given below in table 3 .

Table 3. Length and Width of the Feed Lines

\begin{tabular}{|c|c|c|c|c|}
\hline S.No. & Feed & Length $(\mathrm{mm})$ & Width $(\mathrm{mm})$ & Height $(\mathrm{mm})$ \\
\hline 1. & Feed 1 & 15 & 1 & 0.038 \\
\hline 2. & Feed 2 & 15 & 1 & 0.038 \\
\hline 3. & Feed 3 & 1 & 37 & 0.038 \\
\hline 4. & Feed 4 & 5 & 1 & 0.038 \\
\hline
\end{tabular}

After designing feeds as shown in figure 9.1 the discrete port connected at the feed 4 and the simulation carried out using transient solver with the accuracy of $-30 \mathrm{~dB}$. After simulations the results is obtained of the microstrip patch array.

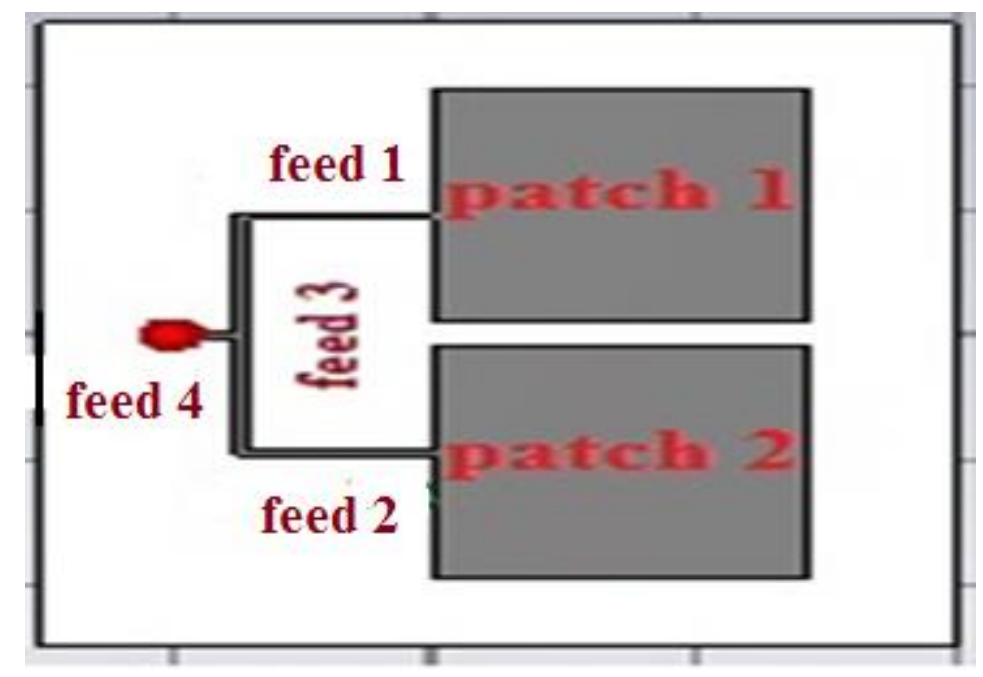

Figure 9.1. Two Element Array 
The reflection coefficient graph for patch array is shown in figure 10. The reflection coefficient of array is $-38.7036 \mathrm{~dB}$ or the return loss is $38.7036 \mathrm{~dB}$ at a frequency of 2.352 $\mathrm{GHz}$. This shows that the now the antenna is radiating strongly so in the array return loss decreases.

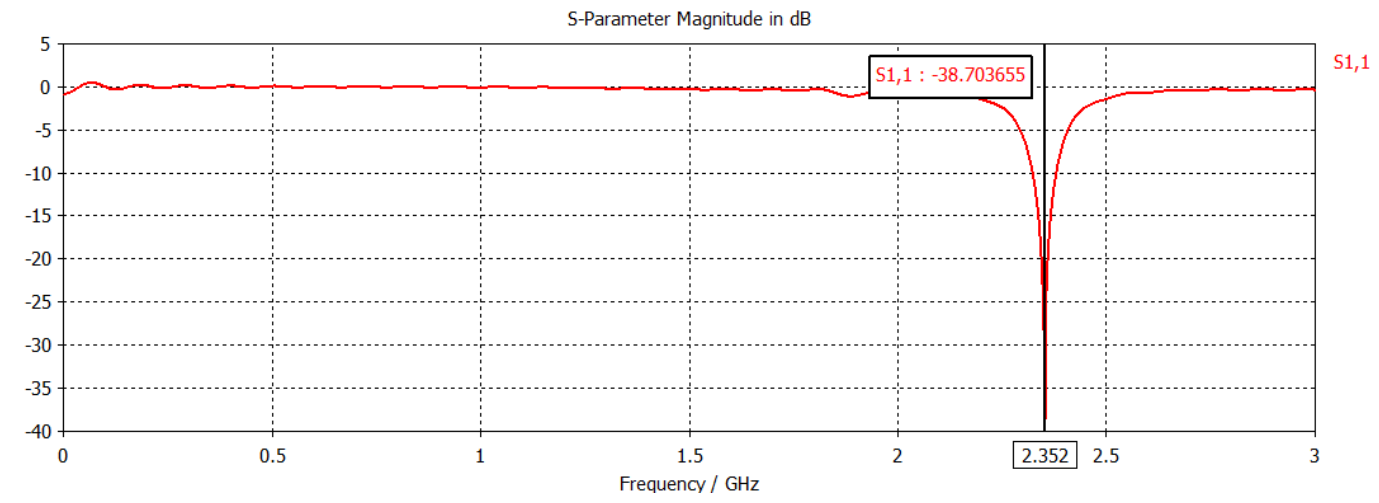

Figure 10. Graph for Reflection Coefficient of Array

The voltage standing wave ratio (VSWR) also calculated for array as shown in figure 11. The value for VSWR is 1.0234. This shows that value of VSWR is also improved and matching is better between feed and patch.

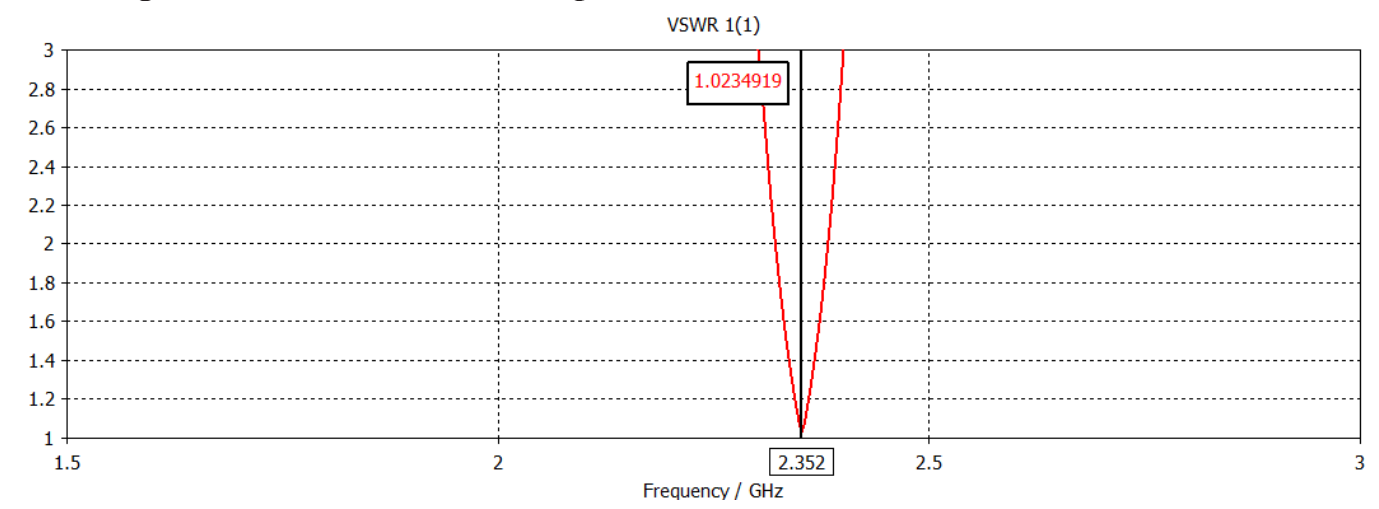

Figure 11. Graph for VSWR of Microstrip Patch Array

The polar plot is a plot of power level magnitude at the different - different angles. So the polar plot for array is plotted in figure 12. In which main lobe magnitude is $8.7 \mathrm{~dB}$ with direction of -10 degree. Angular width $(3 \mathrm{~dB})$ is 88.8 degree while the side lobe level is -12.7 degree. 
Gain Abs $($ Phi $=0)$

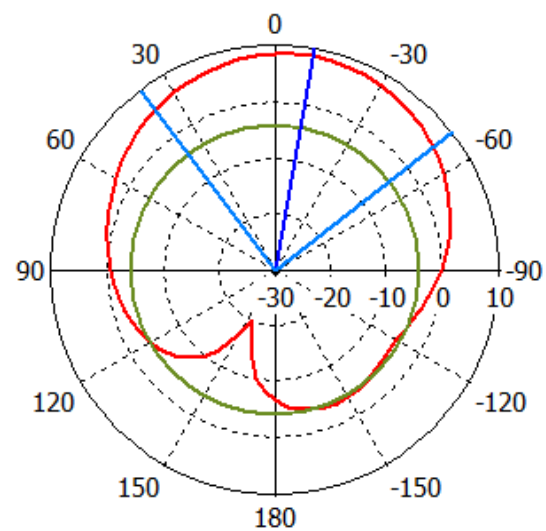

Theta / Degree vs. dB farfield (broadband) [1]

Frequency $=2.4835$

Main lobe magnitude $=8.7 \mathrm{~dB}$ Main lobe direction $=-10.0 \mathrm{deg}$. Angular width $(3 \mathrm{~dB})=88.8 \mathrm{deg}$. Side lobe level $=-12.7 \mathrm{~dB}$

\section{Figure 12. Graph for Polar Plot of Microstrip Patch Array}

The 3D view of the farfield $(k R>>1)$ radiation pattern is shown in figure 13. From this plot the radiation efficiency obtained is $.7321 \mathrm{~dB}$. The total efficiency is $-4.252 \mathrm{~dB}$.
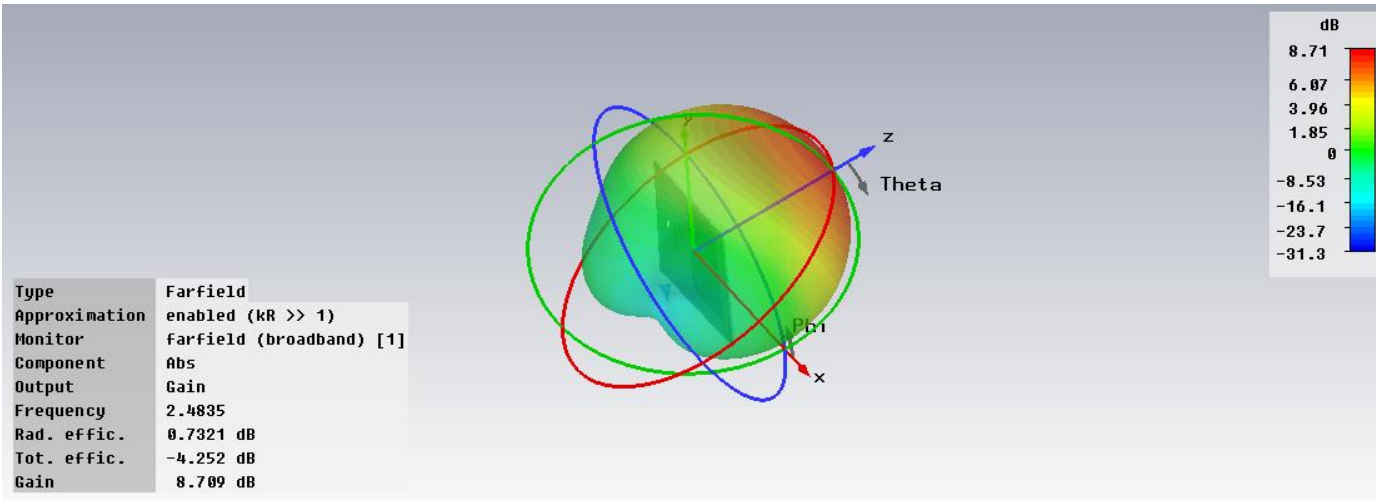

Figure 13. Graph for 3 D View of Polar Plot of Microstrip Patch Array

The graph for gain (IEEE) is plotted in figure 14 which shows the gain is $5.6692 \mathrm{~dB}$ at a frequency of $2.4828 \mathrm{GHz}$.

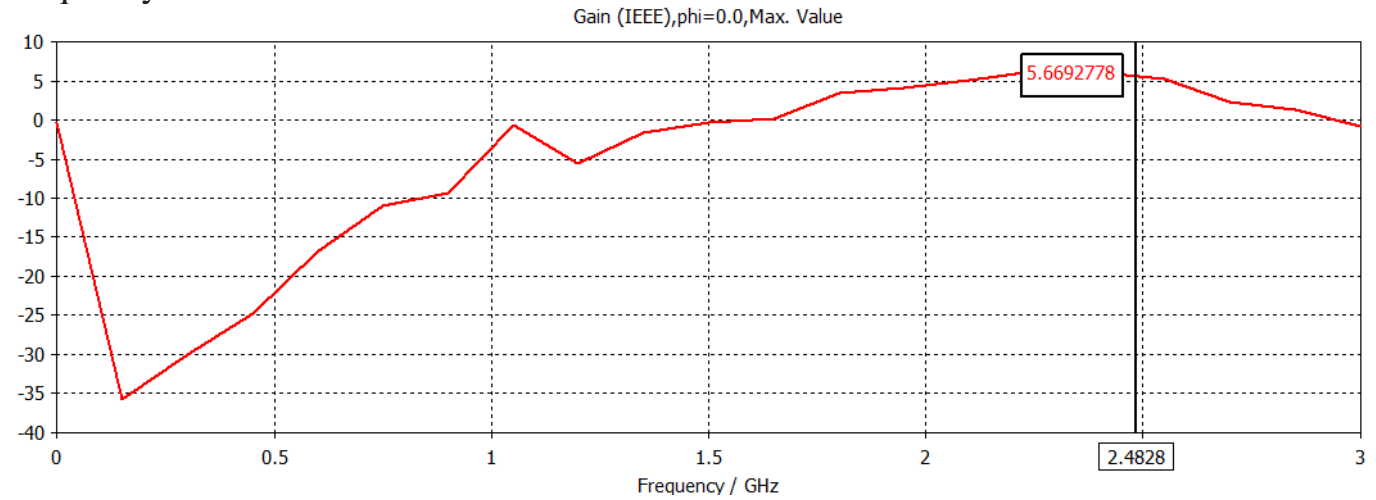

Figure 14. Graph for Gain (IEEE) of Microstrip Patch Array 


\section{Comparison}

The comparison of parameters like reflection coefficient, VSWR, Gain (IEEE) is shown in figure below.

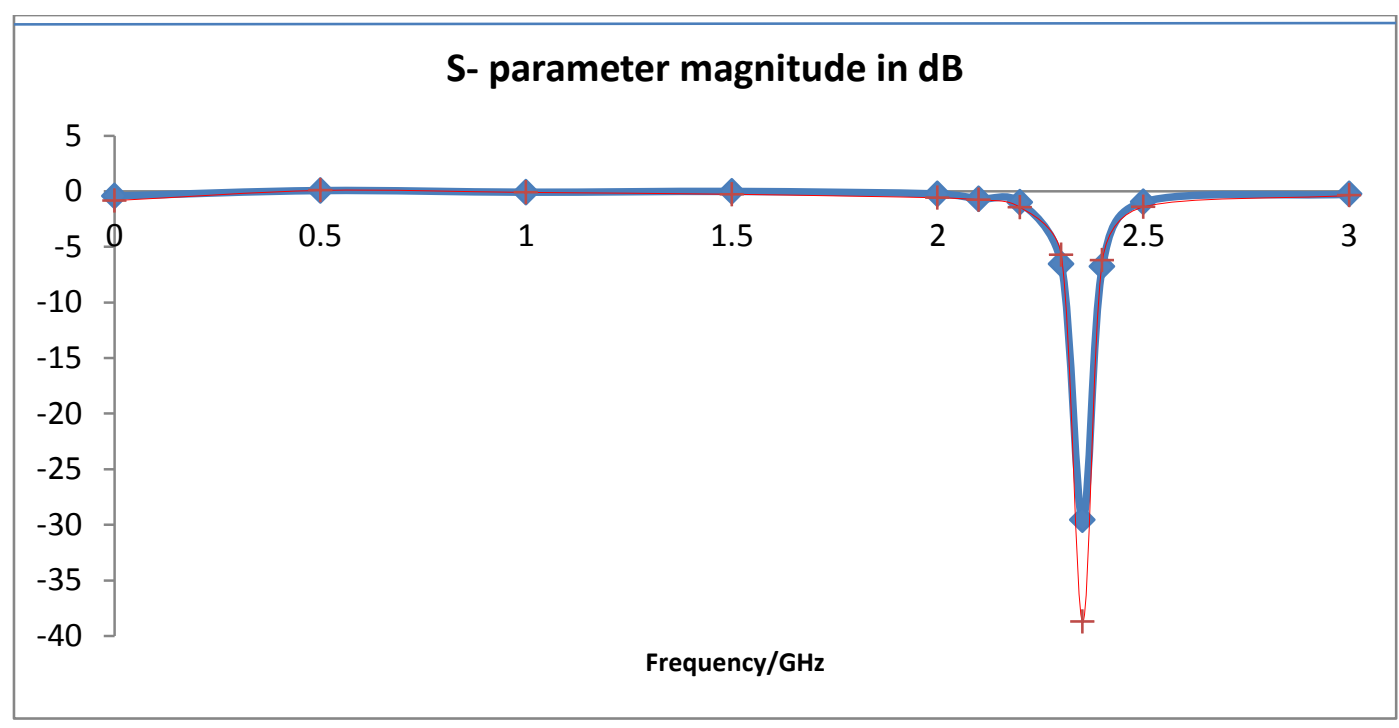

Figure 15. Comparison Between Reflection Coefficient of Single Patch and Array

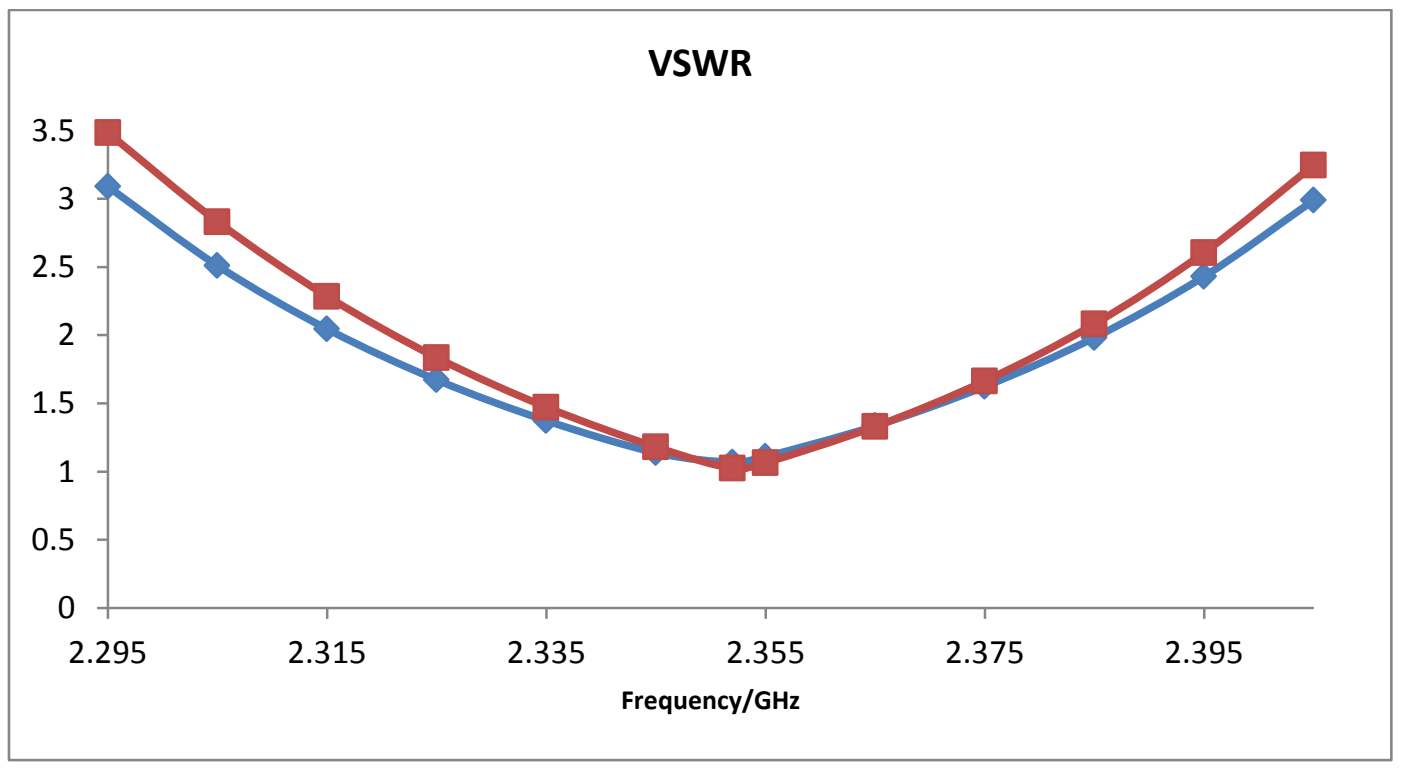

Figure 16. Comparison Between VSWR of Single Patch and Array 


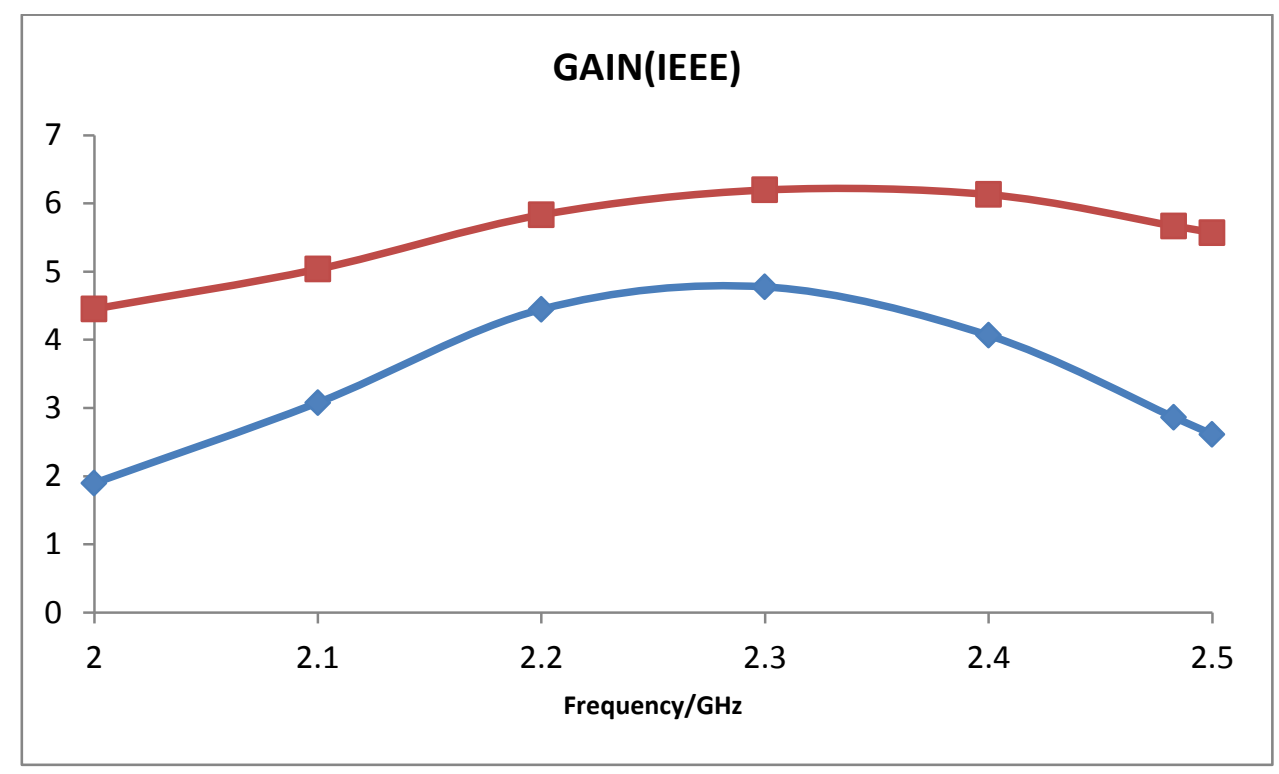

Figure 17. Comparison Between Gain (IEEE) of Single Patch and Array

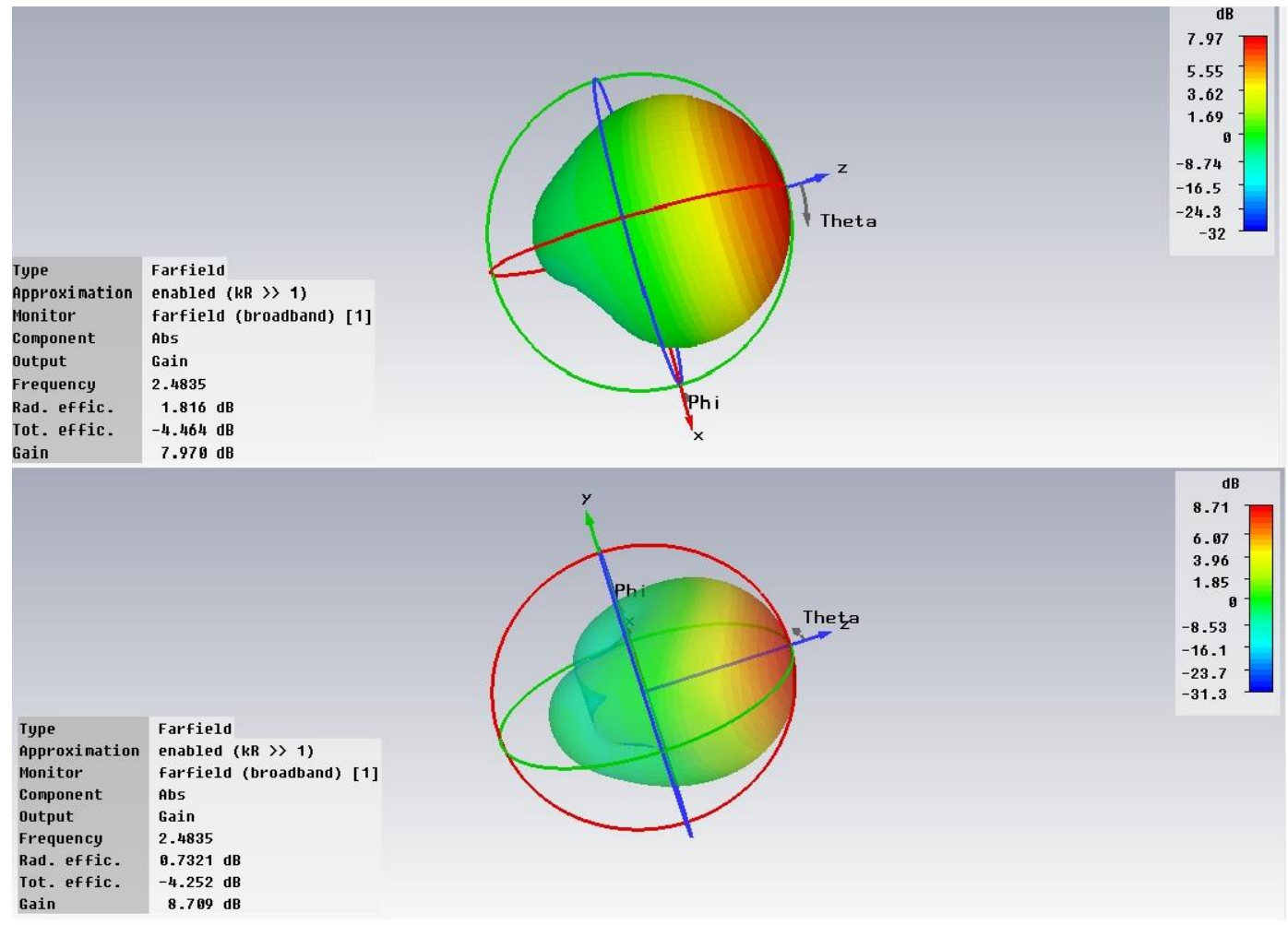

Figure 18. Comparison Between Gain (Abs) of Single Patch and Array

The conclusion derived from all the above figures is listed in table 4. 
Table 4. Comparison Between Single Patch and Array Parameters

\begin{tabular}{|c|c|c|c|}
\hline S.No. & PARAMETER & SINGLE PATCH & ARRAY \\
\hline 1. & Reflection coefficient $\left(\mathrm{S}_{11}\right)$ & -29.5575 & -38.7036 \\
\hline 2. & VSWR & 1.0688 & 1.0234 \\
\hline 3. & Gain(IEEE) & 2.8647 & 5.6692 \\
\hline 4. & Gain $(\mathrm{Abs})$ & 7.970 & 8.709 \\
\hline
\end{tabular}

From table 4 we can see that there is improvement in reflection coefficient \& VSWR improves and gain (IEEE) is increased.

\section{Conclusion}

Microstrip antennas are narrow band antennas with low gain. Gain is an important parameter of microstrip antenna so the gain of antenna has to be increased for applications like observing effects of radiation, RF harvesting. In this paper for enhancement of gain the microstrip array technique is used. In which two rectangular patches of same size and frequency combined in a manner so that return loss or reflection coefficient, VSWR, Gain (IEEE) improved. Hence this paper concludes that there is improvement in Gain (IEEE) and in other parameters also.

\section{References}

[1] "International Commission on Non-Ionizing Radiation Protection (ICNIRP)", Health issues related to the use of hand-held radiotelephones and base transmitters. Health Phys., vol. 70, (1996), pp. 587-593.

[2] J. W. Howell "Microstrip Antennas," IEEE Trans. Antennas Propagat., vol. AP-23, no. 1, pp. 90-93, (1975) January.

[3] G. A. Deschamps, "Microstrip Microwave Antennas," Presented at the Third USAF Symposium on Antennas, (1953).

[4] K. R. Carver, "practical analytical techniques for the microstrip antenna", (1979).

[5] I. J. Bahl and P. Bhartia, "Microstrip Antennas", Artech House, Dedham, MA, (1980).

[6] A. G. Derneryd, "A Theoretical Investigation of the Rectangular Microstrip Antenna Element," IEEE Trans. Antennas Propagat., vol. AP-26, no. 4, pp. 532-535, (1978) July.

[7] B. Halim and D. Tayeb "Gain enhancement of a microstrip patch antenna using a cylindrical electromagnetic crystal substrate," IEEE Trans. Antennas Propagat., vol. 55, no. 11, (2007), pp. 30873092.

[8] "Microstrip Array Antenna with new 2D-Electromagnetic band gap shapes to reduce harmonics and mutual coupling”,PIER C,vol. 12, (2010), pp. 203-213.

[9] S. M. Thamil, D. Rajeshwari, P. Priya and K.N.Shiny, "Performance Effective Design of Bi-Quad Antenna with Parabolic Reflector over Traditional Omni Directional Antenna with Wireless Fidelity (Wi-Fi)", SSRG International Journal of Electronics and Communication Engineering (SSRG-IJECE) vol. 2, no. 3, (2015) March, pp.89-93.

[10] Q. Yongxi, P. Dansieven, R. Vesna, Y. Eli and I. Tatsuo "A novel approach for gain and bandwidth enhancement of patch antennas", RAWCON'98 proceedings, pp. 221-224.

[11] R.Dhanalakshmi, K. Santosh and R. Srinivas, "gain enhancement of slotted microstrip patch antenna using EBG”, IJES, vol. 3, no. 6, pp. 53-57, (2014) June.

[12] A. B.Constantine, "antenna theory analysis and design", $3^{\text {rd }}$ edition.

[13] C. A. Balanis, "antenna theory analysis and design", $3^{\text {rd }}$ edition, chapter 14, pp. 816-820.

[14] T. A. Milligan, "Modern Antenna Design", $2^{\text {nd }}$ edition.

\section{Authors}

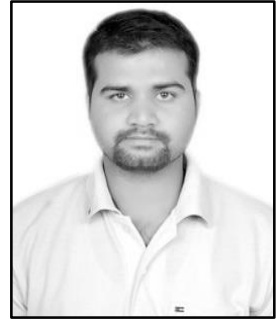

Rahul Dev Mishra was born in 1990, received his Bachelor Degree in 2011 from Scope College of Engineering Bhopal Madhya Pradesh India. Currently he is pursuing masters in Electronics and communication (Microwave Engineering) at Madhav Institute of Technology and Science in Gwalior, India. His research work is microstrip antenna designing to observe the effects of radiations on 
animals.

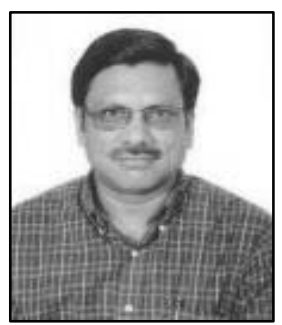

Pramod kumar Singhal was born in 1965. He received his B.E. and Ph.D. in electronics engineering from Jiwaji University, Gwalior, India in 1987 and 1997, respectively and M. Tech degree in microwave electronics from the University of Delhi, India in 1989. Currently, he is working as Professor in Department of Electronics Engineering, Madhav Institute of Technology and Science, Gwalior, India. He has about 90 publications to his credit at national and international level. His research interest includes electromagnetic communication systems, microwave circuits and antennas. Dr. Singhal is a Life Member of the Indian Society for Technical Education (ISTE), the Computer Society of India (CSI), the Institution of Engineers (India), and the Institute of Electronics and Telecommunication Engineers (IETE). 
International Journal of Signal Processing, Image Processing and Pattern Recognition Vol. 9, No. 5 (2016) 